\title{
Skeletal muscle hypertrophy and
} attenuation of cardio-metabolic risk factors (SHARC) using functional electrical

\section{stimulation-lower extremity cycling in persons with spinal cord injury: study protocol for a randomized clinical trial}

Ashraf S. Gorgey ${ }^{1,2^{*}}$ (D), Refka E. Khalii ${ }^{1}$, John C. Davis ${ }^{1}$, William Carter ${ }^{2}$, Ranjodh Gill ${ }^{3,4}$, Jeannie Rivers ${ }^{4}$, Rehan Khan $^{5}$, Lance L. Goetz ${ }^{1,2}$, Teodoro Castillo ${ }^{1,2}$, Timothy Lavis ${ }^{1,2}$, Adam P. Sima ${ }^{6}$, Edward J. Lesnefsky ${ }^{7,8}$,

Christopher C. Cardozo 9,10 and Robert A. Adler ${ }^{3,4}$

\begin{abstract}
Background: Persons with spinal cord injury (SCl) are at heightened risks of developing unfavorable cardiometabolic consequences due to physical inactivity. Functional electrical stimulation (FES) and surface neuromuscular electrical stimulation (NMES)-resistance training (RT) have emerged as effective rehabilitation methods that can exercise muscles below the level of injury and attenuate cardio-metabolic risk factors. Our aims are to determine the impact of 12 weeks of NMES +12 weeks of FES-lower extremity cycling (LEC) compared to 12 weeks of passive movement +12 weeks of FES-LEC on: (1) oxygen uptake $\left(\mathrm{VO}_{2}\right)$, insulin sensitivity, and glucose disposal in adults with $\mathrm{SCl}$; (2) skeletal muscle size, intramuscular fat (IMF), and visceral adipose tissue (VAT); and (3) protein expression of energy metabolism, protein molecules involved in insulin signaling, muscle hypertrophy, and oxygen uptake and electron transport chain (ETC) activities.

Methods/Design: Forty-eight persons aged 18-65 years with chronic (> 1 year) SCI/D (AIS A-C) at the C5-L2 levels, equally sub-grouped by cervical or sub-cervical injury levels and time since injury, will be randomized into either the NMES + FES group or Passive + FES (control group). The NMES + FES group will undergo 12 weeks of evoked RT using twice-weekly NMES and ankle weights followed by twice-weekly progressive FESLEC for an additional 12 weeks. The control group will undergo 12 weeks of passive movement followed by 12 weeks of progressive FES-LEC. Measurements will be performed at baseline (B; week 0), post-intervention 1 (P1; week 13), and post-intervention 2 (P2; week 25), and will include: $\mathrm{VO}_{2}$ measurements, insulin sensitivity, and glucose effectiveness using intravenous glucose tolerance test; magnetic resonance imaging to measure muscle, IMF, and VAT areas; muscle biopsy to measure protein expression and intracellular signaling; and mitochondrial ETC function.

\footnotetext{
* Correspondence: ashraf.gorgey@va.gov

'Spinal Cord Injury \& Disorders Service, Hunter Holmes McGuire VA Medical Center, Richmond, VA, USA

${ }^{2}$ Department of Physical Medicine \& Rehabilitation, Virginia Commonwealth

University, Richmond, VA, USA

Full list of author information is available at the end of the article
}

(c) The Author(s). 2019 Open Access This article is distributed under the terms of the Creative Commons Attribution 4.0 International License (http://creativecommons.org/licenses/by/4.0/), which permits unrestricted use, distribution, and reproduction in any medium, provided you give appropriate credit to the original author(s) and the source, provide a link to the Creative Commons license, and indicate if changes were made. The Creative Commons Public Domain Dedication waiver (http://creativecommons.org/publicdomain/zero/1.0/) applies to the data made available in this article, unless otherwise stated. 
(Continued from previous page)

Discussion: Training through NMES + RT may evoke muscle hypertrophy and positively impact oxygen uptake, insulin sensitivity, and glucose effectiveness. This may result in beneficial outcomes on metabolic activity, body composition profile, mitochondrial ETC, and intracellular signaling related to insulin action and muscle hypertrophy. In the future, NMES-RT may be added to FES-LEC to improve the workloads achieved in the rehabilitation of persons with $\mathrm{SCl}$ and further decrease muscle wasting and cardio-metabolic risks.

Trial registration: ClinicalTrials.gov, NCT02660073. Registered on 21 Jan 2016.

Keywords: Neuromuscular electrical stimulation, Functional electrical stimulation, Resistance training, Spinal cord injury

\section{Background}

Spinal cord injury (SCI) is a devastating medical condition that results in reduced aerobic fitness, glucose intolerance, and insulin resistance due to autonomic dysfunction, muscle wasting, increased regional and total body fat mass, and relative inactivity [1]. Of the more than 46,000 veterans with SCI-related disability, $>60 \%$ are overweight or obese, $>50 \%$ are glucose intolerant, and $20 \%$ are diabetic [2, 3]. There are 11,000-12,000 new cases of SCI in the United States annually. The prevalence of individuals with SCI has been estimated to be 250,000-400,000 with an estimated $14 \%$ growth in prevalence since 1988 [4, 5]. In the last two decades, costs of SCI in the United States have increased with a concomitant decline in mortality over the first year after SCI [1]. The average initial charge per case is in the range of $\$ 342,000-\$ 1,048,000$ for acute stabilization and rehabilitation, with annual charges thereafter in the range of $\$ 41,000-\$ 182,000[4,6,7]$. It has been estimated that the estimated lifetime costs that result from SCI is 7.3-12 million dollars $[4,6]$.

The Centers for Disease Control and Prevention (CDC) and the American College of Sports Medicine have recommended $30 \mathrm{~min}$ of daily exercise to prevent the occurrence of health-related and obesity-related secondary complications [8]. Furthermore, guidelines were recently published by the International Spinal Cord Injury Society (ISCoS) suggesting 2-3 days per week of moderate to vigorous physical activity to lessen secondary co-morbidities [9]. However, there are several barriers that interfere with maximizing the benefits of any exercise protocol [10]. To offset some of these barriers, exercising skeletal muscle below the level of injury may enhance several cellular activities and whole-body metabolism [11-13]. Skeletal muscles serve as a large endocrine gland that controls interplay between musculoskeletal systems and other physiological systems [14-16]. Previous work demonstrated that skeletal muscle hypertrophy releases important myokines that may regulate atrophic pathways, bone, and endocrine glands. Thus, it is crucial to maintain the skeletal muscle vitality sublesionally to maintain the integrity of other physiological systems [11-13].
Functional electrical stimulation (FES) is a form of neuromuscular electrical stimulation (NMES) which provides stimulation of selected muscles in a coordinated manner resulting in a functional pattern such as walking, cycling, or rowing. This is contrary to surface NMES which is used for a single or multiple muscle groups to exercise or to move specific joint, but without the intention of producing a functional or coordinated movement [17]. FES-lower extremity cycling (LEC) is limited by the low exercise intensity, low peak oxygen uptake $(0.4 \mathrm{~L} / \mathrm{min})$, and rapid muscle fatigue, which renders FES-LEC training a suboptimal modality to increase gain in lean mass and improve metabolic health after SCI $[18,19]$. This may result from a mismatch when converting metabolic energy into mechanical energy.

Neuromuscular electrical stimulation (NMES) has been used to evoke exercise-induced resistance training (RT) using regular ankle weights in individuals with chronic SCI [20-24]. Several research groups demonstrated the efficacy of this approach in evoking robust muscle hypertrophy [21, 24, 25]. Dudley et al. showed that eight weeks of twice-weekly NMES RT reverted knee extensor muscle size to $75 \%$ of original size at six weeks after SCI [21]. Follow-up studies reported a 35-39\% increase in muscle hypertrophy and $33 \%$ fatigue resistance of the trained knee extensors $[22,23]$. Gorgey et al. noted that 12 weeks of twiceweekly NMES RT elicited an increase in skeletal muscle size of $>35 \%$, decreased IMF and VAT by $25 \%$, and increased insulin sensitivity and insulin growth factor-1 (IGF-1) by 25\% [23]. Finally, Ryan et al. noted improvement in mitochondrial capacity by $25 \%$ following 16 weeks of twice-weekly evoked NMES $\mathrm{RT}$ in persons with chronic complete SCI [24]. A recent study demonstrated that 16 weeks of NMES-RT combined with testosterone replacement therapy (TRT) resulted in a 43\% muscle hypertrophy of the knee extensor and 21\% increase in thigh muscle cross-sectional area (CSA) accompanied with 14-17\% increase in daily basal metabolic rate (BMR) compared to TRT only. [25] 
The objectives of the current trial are to determine the impact of evoking skeletal muscle hypertrophy using surface NMES and ankle weights before conducting FES-LEC on oxygen uptake, insulin sensitivity, and glucose effectiveness (primary endpoint variables) compared to those who undergo passive movement and FES training only. The primary question is: does evoking skeletal muscle hypertrophy lead to improvement in metabolic health benefits as outlined in Fig. 1? This prospective randomized clinical trial will also shed light on the mechanism and signaling pathways responsible for evoking hypertrophy, enhancing energy, and substrate utilization as well as improving glucose metabolism.

We hypothesize that the addition of 12 weeks of NMES combined with RT before FES-LEC will evoke skeletal muscle hypertrophy, decrease IMF and visceral fat, and enhance gains in aerobic fitness and insulin sensitivity observed during a subsequent 12-week period of exercise by FES-LEC. We also hypothesize that when NMES RT is administered before FES-LEC, the intracellular signaling related to insulin action (IRS1, Glut4) and muscle growth (Akt and mTOR) will be improved. These effects of NMES RT may further enhance the beneficial actions of FES-LEC on metabolic profile, body composition profile, and mitochondrial electron transport chain (ETC) and intracellular signaling related to insulin action and muscle growth.

\section{Methods}

\section{Study design}

A five-year, two-site, randomized controlled study is proposed to investigate the efficacy of NMES + FES versus Passive + FES (control group) on health-related secondary complications after SCI (Table 1). A third site will be used for protein and RNA analysis that will generated from muscle biopsy samples. Patches of muscle biopsy samples will be shipped overnight at the completion of the trial for analysis purpose (see below). All training aspects will be conducted at the SCI Exercise Body Composition Laboratory and MRI Research center located at the McGuire VA Medical Center (VAMC) and the Clinical Research Center (CRC) located at Virginia Commonwealth University (VCU). All participants will undergo metabolic studies, body composition assessments using anthropometry, dual X-ray absorptiometry and magnetic resonance imaging (MRI), and muscle biopsies. After informed consent, each individual will undergo a complete physical examination, including neurological assessment, and International Standards for Neurological Classification of Spinal Cord Injury (ISNCSCI), formerly known as the "ASIA" exam.

Additionally, MRI scans will be obtained for trunk VAT, lower extremity skeletal muscles, and IMF CSAs $[2,3]$. Participants will then be escorted to the VCU CRC and will remain in the CRC overnight for metabolic testing. This procedure will be used for the three study visits (baseline and post-interventions 1 and 2). Resting blood pressure and fasting metabolic labs will be obtained including HbA1c, as well as lipid panels, Creactive protein (CRP), interleukin-6 (IL-6), tumor necrosis factor alpha (TNF- $\alpha$ ), and free fatty acids (FFA). This will be followed by an intravenous glucose tolerance test (IVGTT). The vastus lateralis muscle will be biopsied to measure proteins expression and myosin heavy chain expression and to determine mitochondrial ETC and enzymatic activities. The design of the study is outlined in Fig. 2.

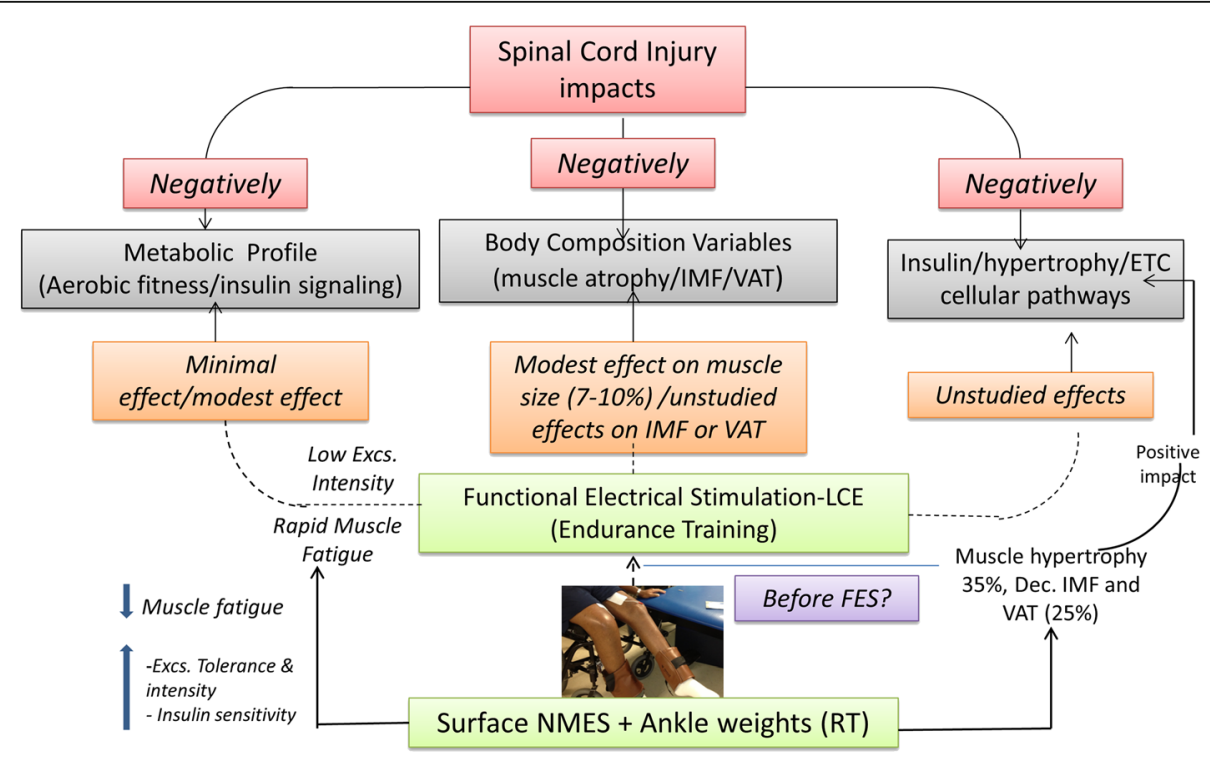

Fig. 1 Rationale of the study. Briefly summarizes the negative impacts of SCl on body composition and cardiometabolic prolife and how adding NMES-RT to FES-LEC training may help to alleviate these health-related consequences and serve as a rehabilitation approach for persons with SCI 
Table 1 Randomization of individuals with motor complete SCl using block randomization based on level of injury (paraplegia vs tetraplegia) and time since injury (less than or more than 10 years) into either NMES + FES or PM + FES

\begin{tabular}{|c|c|c|c|c|}
\hline Subject ID & Assignment & Baseline 1 & Post-intervention 1 & Post-intervention 2 \\
\hline $001-10123$ & $\mathrm{PM}+\mathrm{FES}$ & $C$ & C & $C$ \\
\hline 002-10187 & $P M+F E S$ & C & C & C \\
\hline 003-10122 & NMES + FES & C & C & C \\
\hline 004-10006 & NMES + FES & C & C & C \\
\hline 005-10128 & NMES + FES & C & C & C \\
\hline 006-10142 & $P M+F E S$ & C & C & $x$ \\
\hline 007-10179 & NMES + FES & C & C & C \\
\hline 008 & N/A & $x$ & $x$ & $x$ \\
\hline 009-10135 & NMES + FES & C & Withdraw & $x$ \\
\hline 010-10177 & $P M+F E S$ & C & C & C \\
\hline $011-10064$ & $P M+F E S$ & C & C & C \\
\hline 012-10181 & NMES+FES & C & C & C \\
\hline 013-10026 & $P M+F E S$ & Withdraw & $x$ & $x$ \\
\hline 014-10149 & NMES + FES & C & C & C \\
\hline 015-10089 & NMES + FES & C & C & C \\
\hline 016-10140 & $P M+F E S$ & C & C & C \\
\hline 017-10178 & $P M+F E S$ & C & C & C \\
\hline 018-10154 & $\mathrm{PM}+\mathrm{FES}$ & C & C & C \\
\hline 019-10034 & NMES + FES & C & C & C \\
\hline 020-10176 & NMES + FES & C & C & C \\
\hline $021-10163$ & NMES + FES & Withdraw & $x$ & $x$ \\
\hline 022-10130 & $\mathrm{PM}+\mathrm{FES}$ & C & C & C \\
\hline 023-10113 & $P M+F E S$ & C & C & Withdraw \\
\hline 024-10186 & NMES + FES & C & C & C \\
\hline 025 & N/A & $x$ & $x$ & $x$ \\
\hline 026-10097 & $P M+F E S$ & withdraw & $x$ & $x$ \\
\hline $027-10148$ & $P M+F E S$ & C & C & C \\
\hline 028-10092 & NMES + FES & C & C & Withdraw \\
\hline 029-10180 & NMES + FES & C & C & C \\
\hline 030-10019 & $P M+F E S$ & C & C & C \\
\hline 031 & N/A & $x$ & $x$ & $x$ \\
\hline $032-10160$ & NMES + FES & C & C & $x$ \\
\hline 033-10052 & $P M+F E S$ & C & C & $x$ \\
\hline 034 & N/A & $x$ & $x$ & $x$ \\
\hline 035 & Pending randomization & & & \\
\hline 036 & TBR & & & \\
\hline 037 & TBR & & & \\
\hline 038 & TBR & & & \\
\hline 039 & TBR & & & \\
\hline 040 & TBR & & & \\
\hline 041 & TBR & & & \\
\hline 042 & TBR & & & \\
\hline 043 & TBR & & & \\
\hline
\end{tabular}


Table 1 Randomization of individuals with motor complete SCl using block randomization based on level of injury (paraplegia vs tetraplegia) and time since injury (less than or more than 10 years) into either NMES + FES or PM + FES (Continued)

\begin{tabular}{llll}
\hline Subject ID & Assignment & Baseline 1 & Post-intervention 1 \\
\hline 044 & TBR & & \\
045 & TBR & & \\
046 & TBR & \\
047 & TBR & \\
048 & TBR & \\
\hline
\end{tabular}

C completed, NA not assigned for \#008, 025, and 031, TBR to be recruited later

Before baseline 1, randomization was performed into NMES + FES or PM + FES groups. Post-intervention 1 ( $n=23)$ was conducted after 12 weeks of intervention of either NMES or PM. Post-intervention $2(n=20)$ was conducted after 12 weeks of FES

\section{Recruitment strategy}

The recruitment process started in October 2015 and will end in September 2020. Forty-eight participants will be randomly assigned into either NMES + FES or Control + FES groups for 24 weeks. The participants will be matched based on level of injury (tetraplegia versus paraplegia) and time since injury (less than versus more than 10 years) using block randomization using a $2 \times 2$ design developed by the study statistician. Randomization was conducted using n-query computer program at the baseline before enrollment in the trial (Table 1). Current recruitment status is outlined in Table 2.

\section{Participant inclusion and exclusion criteria}

All participants will be aged 18-65 years, men/women [24], more than one year after $\mathrm{SCI}$, with body mass index $(\mathrm{BMI}) \leq$ $30 \mathrm{~kg} / \mathrm{m}^{2}$ [23]. Participants with traumatic motor complete or incomplete C5-L2 level of injury, the American Spinal Injury Association (ASIA) Impairment Scale (AIS) classification $\mathrm{A}, \mathrm{B}$, or $\mathrm{C}$ will be considered for the trial. Participants with any of the following pre-existing medical conditions will be excluded: cardiovascular disease; uncontrolled type II diabetes mellitus; uncontrolled hypertension; insulin dependence; pressures sores stage 3 or greater; hematocrit $>50 \%$; symptomatic urinary tract infection; or participants with neck of femur or total body osteoporosis (T-score $\leq-2.5$ according to the World Health Organization guidelines.) [26].

\section{Interventions}

\section{Resistance training}

A recent video publication provided full details on the NMES-RT protocol [27]. Briefly, NMES will be applied to the knee extensor muscles via surface electrodes to induce concentric-eccentric actions. Two $8 \times 10 \mathrm{~cm}^{2}$ adhesive carbon electrodes will be placed on the skin over the knee extensor muscle group. Current from the stimulator will be manually increased in 5-s intervals to evoke full knee extension against gravity followed by gradual reduction of current to induce eccentric action during relaxation. Training will be performed twice-weekly for 12 weeks. Each training session will consist of four sets of 10 repetitions of NMES with $30 \mathrm{~Hz}, 450 \mu$ s pulses, and a current sufficient to evoke full knee extension

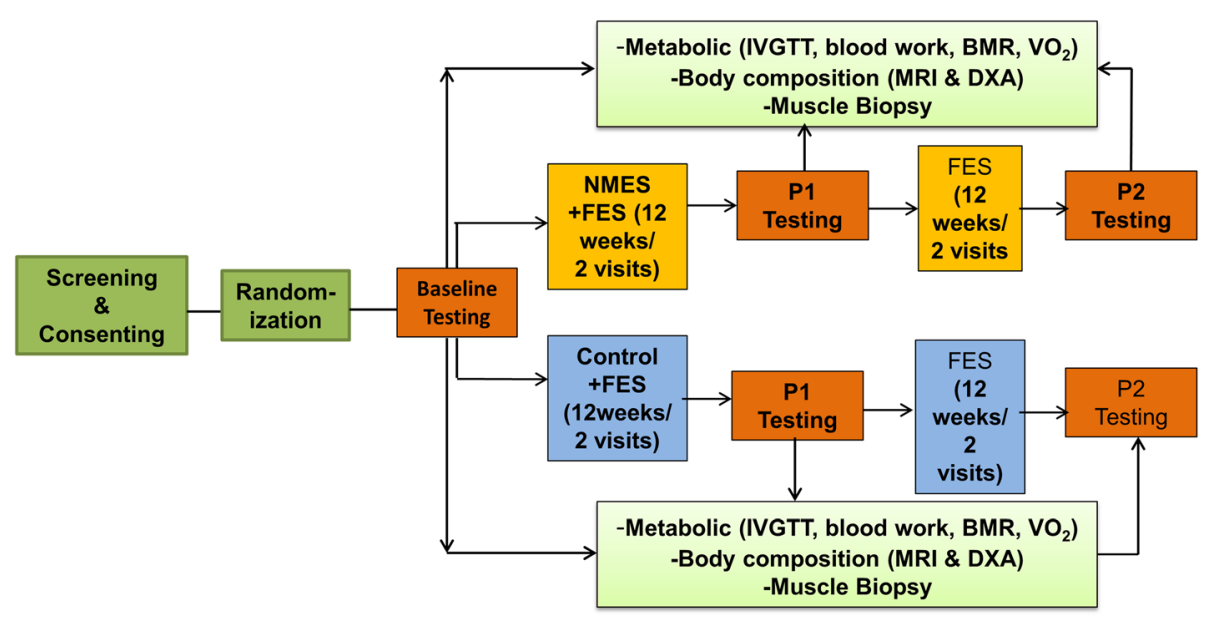

Fig. 2 The study timeline and procedure are highlighted. After screening and consent, participants will be randomized into one of two testing groups. Each participant will undergo baseline testing (B) before beginning NMES + FES or Control + FES. Each group will then be tested for metabolic, body, and muscle composition (P1) after a 12-week period. Each group will then complete 12 weeks of FES followed by another bout of testing (P2) 
Table 2 The breakdown of the number of persons who have been contacted for the study, who have completed the study, or are currently actively participating in the study. All others have either failed screening or withdrawn from the study

\begin{tabular}{|c|c|c|c|c|c|}
\hline \multirow[b]{3}{*}{ Timepoint** } & \multicolumn{5}{|c|}{ Study period } \\
\hline & $\begin{array}{l}\text { Pre- } \\
\text { Enrolment }\end{array}$ & \multirow[t]{2}{*}{ Enrolment } & \multirow[t]{2}{*}{ Baseline } & \multicolumn{2}{|c|}{$\begin{array}{l}\text { Post- } \\
\text { intervention }\end{array}$} \\
\hline & 1 & & & 1 & 2 \\
\hline Pre-enrolment: & 536 & & & & \\
\hline Not-interested & 354 & & & & \\
\hline Expressed interest & 182 & & & & \\
\hline Phone screen Failure & 68 & & & & \\
\hline Physical screen failure & 50 & & & & \\
\hline Qualified and Enrolled & 64 & & & & \\
\hline Enrolment $[1=\mathrm{a}+\mathrm{b}]$ & & 64 & & & \\
\hline No Show ${ }^{(a)}$ & & 29 & & & \\
\hline $\begin{array}{l}\text { Consented }^{(b)}[2=c+d \\
+e+F]\end{array}$ & & 35 & & & \\
\hline Screen Failure ${ }^{(c)}$ & & 5 & & & \\
\hline Withdrawn (d) & & 6 & 3 & 1 & 2 \\
\hline Completed $^{(e)}$ & & 21 & & & \\
\hline Currently Active ${ }^{(t)}$ & & 3 & & & \\
\hline $\begin{array}{l}\text { Pending future } \\
\text { enrollment }(\mathrm{g})\end{array}$ & & 13 & & & \\
\hline $\begin{array}{l}\text { Total sample size }[3= \\
b+g]\end{array}$ & & 48 & & & \\
\hline \multicolumn{6}{|l|}{ Interventions: } \\
\hline [NMES+FES] & & 15 & 14 & 13 & 12 \\
\hline [Control + FES] & & 15 & 13 & 13 & 12 \\
\hline \multicolumn{6}{|l|}{ Assessments: } \\
\hline $\begin{array}{l}\text { [Body Composition } \\
\text { Variables] }\end{array}$ & & & $x$ & $x$ & $x$ \\
\hline [Metabolic variables] & & & $x$ & $x$ & $x$ \\
\hline $\begin{array}{l}\text { [Muscle Biopsy } \\
\text { variables] }\end{array}$ & & & $x$ & $x$ & $x$ \\
\hline $\begin{array}{l}\text { [Torque and fatigue } \\
\text { variables] }\end{array}$ & & & $x$ & $x$ & $x$ \\
\hline
\end{tabular}

[28-30]. The first week of the RT will be conducted with no ankle weights to ensure that the knee extensor muscles can extend the weight of the lower leg against gravity $[3,23]$. Once full knee extension is achieved in a sitting position, an increment of $2 \mathrm{lbs}$ will be used on a weekly basis with the criteria that full knee extension should be achieved before further increases in load [21-24, 31].

\section{Passive range of motion for control}

A member of the research team supports the leg proximal to the ankle joints and moves it from $90^{\circ}$ knee flexion close to full knee extension. The leg will be maintained up for $5 \mathrm{~s}$ and returned down for $5 \mathrm{~s}$. The passive movements will be repeated in the same fashion described in RT protocol: 10 reps for the right leg followed by 10 reps for the left leg for a total of four sets of 10 reps.

\section{Functional electrical stimulation-lower extremity cycling}

A recent video publication provided full details on the FES-LEC protocol [27]. Briefly, rides will be performed with each individual using conductive adhesive gel electrodes [19, 32]. Rectangular adhesive electrodes are placed on the skin of the knee extensor, hamstrings, and gluteus maximus muscle groups. Pulse frequency will be set at $33.3 \mathrm{~Hz}$, pulse duration at $350 \mu \mathrm{s}$, and resistance will be adjusted every $10 \mathrm{~min}$ to maintain a speed of 40 $45 \mathrm{rpm}$ (RPM). Table 3 highlights the progression of resistance in $0.5-\mathrm{Nm}$ increments per 10 -min stage over the course of 12 weeks. The progression in resistance was customized based on the individual's performance riding the FES-LEC over 12 weeks. Initially, the servomotor of the bike is permitted to assist during the warm-up phase $(5 \mathrm{~min})$ and during training to reduce muscle spasms. Participants are then allowed 2-3 min of rest between each 10-min stage. Time to maximum (100\%) current amplitude, power, and distance covered will be recorded at the end of each stage to determine whether these parameters improved in both groups (NMES + FES versus control). The fatigue threshold will be set at 18 RPM; if RPM falls below 18 RPM, the bike will automatically shift from active to passive cycling (cool-down). During the 3-min cool-down period, participants will be passively cycled with no electrical stimulation. The cool-down period will then be followed by $5 \mathrm{~min}$ of recovery, during which the participant will be still connected to the bike but in a complete resting position. Heart rate will be monitored every $30 \mathrm{~s}$ and blood pressure every $2 \mathrm{~min}$.

The use of NMES-RT or FES-LEC may result in the following potential harms and complications:

1. Light-headedness, shortness of breath, and altered heart rate and blood pressure leading to autonomic dysreflexia. Muscle soreness of the neck, upper back, shoulders, arms, and hands;

2. Fracture of the exercising bones;

3. Autonomic dysreflexia (slow heart rate, high blood pressure, headache flushing, and sweating) which may be life-threatening;

4. Skin irritations or pressure injuries from shear stress that may lead to breaking the skin;

5. Fainting or heart attacks.

Blood pressure will be continuously monitored during exercising sessions to ensure there are no signs of 
orthostatic hypotension or autonomic dysreflexia; participants will be regularly checked for any changes in their physical status or health compared to their initial admission in the study and the SCI provider will be notified immediately. Before admission to the study, participants will undergo DXA scans (see below) to ensure adequate bone health-especially at the hip joints ( $\mathrm{T}$ scores $<-2.5 \mathrm{SD}$ ), distal femur, and proximal tibia (bone mineral density should be $>0.6 \mathrm{~g} / \mathrm{cm}^{2}$ ) - to reduce the likelihood of fracture during exercising. The skin will be checked continuously on a regular basis before and after removal of the electrodes to ensure there is no redness or tendency to develop skin irritations and/or pressure injuries.

Other unanticipated adverse events will be monitored throughout the study via exams, vital signs, laboratory tests, review of medical charts, and verbal concerns voiced by the participant or an associated caregiver. Finally, data safety monitoring board of independent research investigators will annually review the study-related adverse events, adequacy of individuals' compliance, and adherence to the protocol.

\section{Measurements}

\section{Metabolic studies}

\section{Dietary records and basal metabolic rate}

Each participant will follow a standard diet pattern during the entire period of the study (45\% carbohydrate, $35 \%$ fat, and $25 \%$ protein) to balance dietary habits between both groups [23]. All participants will be asked to complete a three-day food record monitoring their energy intake each week. Previous work showed that three-day records are equivalent to five-day records in reporting caloric intake and percentage macronutrients [28]. Caloric needs will be determined using individuals measured BMR. The diaries will be evaluated weekly by the dietitian and monthly feedback will be provided via phone interview or secure email communication to ensure adherence to the recommended dietary plan throughout the study. All participants will meet with the dietitian three times: at baseline, P1, and P2.
After an overnight fast for $10-12 \mathrm{~h}$, participants will be kept in a dark room for $20-30 \mathrm{~min}$ to attain a resting state, during which BMR will be measured by using a canopy that covers the whole head and a portable COSMED K4b2 (COSMED USA, Chicago, IL, USA). BMR and respiratory exchange ratio (RER) will be recorded by indirect calorimetry $[3,33,34]$.

\section{Serum total, free testosterone, IGF, FFA}

Total testosterone measurements will be performed by radioimmunoassay after sample extraction and column chromatography. The interassay coefficient of variation (CV) is $12.5 \%$ or less for all quality control samples analyzed. Free testosterone concentrations will be calculated by measuring sex hormone binding globulin (SHBG) and albumin (http://www.issam.ch/freetesto.htm) [35]. Plasma IGF-I and IGFBP-3 concentrations will be measured by immunoluminometric assay (Quest Diagnostics, Madison, NJ, USA) and RIA (Diagnostics Systems Laboratories Inc., Webster, TX, USA), respectively. A total of $10 \mathrm{~mL}$ of blood will be collected from the indwelling venous catheter and lipid profile (HDL-C, LDL-C, total cholesterol, and TG) will be determined using standard analyses procedures.

\section{Inflammatory biomarkers}

Before starting the IVGTT and following a 12-h fast, blood will be collected from the indwelling venous catheter and CRP, IL- 6 , TNF- $\alpha$, and FFA will be determined by the VCU-CRC using available enzyme-linked immunosorbent assay (ELISA) assay kits [36, 37].

\section{Intravenous glucose tolerance test: primary outcome variables}

An IVGTT will be used to determine insulin sensitivity and glucose effectiveness [38, 39]. Each individual will undergo an IVGTT before (baseline) and 12 weeks after interventions (Post 1 and Post 2). After a 10-12-h fast, an indwelling catheter with an intravenous saline drip $(0.9 \% \mathrm{NaCl})$ will be placed; after $20 \mathrm{~min}$ of glucose injection, a bolus of insulin $(0.02 \mathrm{U} / \mathrm{kg})$ will be injected to

Table 3 Progression of resistance in 0.5-Nm increments per 10-min stage

\begin{tabular}{|c|c|c|c|c|c|c|c|}
\hline & \multicolumn{3}{|l|}{ Visit 1} & \multicolumn{3}{|l|}{ Visit 2} & \multirow[t]{2}{*}{ Comment } \\
\hline & $\begin{array}{l}\text { Stage } 1 \\
\text { (10 min) }\end{array}$ & $\begin{array}{l}\text { Stage } 2 \\
\text { (10 min) }\end{array}$ & $\begin{array}{l}\text { Stage } 3 \\
\text { (10 min) }\end{array}$ & $\begin{array}{l}\text { Stage } 1 \\
(10 \mathrm{~min})\end{array}$ & $\begin{array}{l}\text { Stage } 2 \\
(10 \mathrm{~min})\end{array}$ & $\begin{array}{l}\text { Stage } 3 \\
\text { (10 min) }\end{array}$ & \\
\hline $\begin{array}{l}\text { Week } \\
1\end{array}$ & $1 \mathrm{Nm}$ & $1.5 \mathrm{Nm}$ & 2.0 & $1 \mathrm{Nm}$ & 1.5 & 2.0 & $\begin{array}{l}\text { If completing the } 2 \text { visits without the motor turned on, } \\
\text { paradigm will change in week } 2\end{array}$ \\
\hline $\begin{array}{l}\text { Week } \\
2\end{array}$ & $1.5 \mathrm{Nm}$ & 2.0 & 2.5 & $1.5 \mathrm{Nm}$ & 2.0 & 2.5 & $\begin{array}{l}\text { If the motor tuned on, the same paradigm will be } \\
\text { maintained in week } 3\end{array}$ \\
\hline $\begin{array}{l}\text { Week } \\
3\end{array}$ & $1.5 \mathrm{Nm}$ & 2.0 & 2.5 & $1.5 \mathrm{Nm}$ & 2.0 & 2.5 & $\begin{array}{l}\text { If completing the } 2 \text { visits without the motor turned on, } \\
\text { paradigm will change in week } 4\end{array}$ \\
\hline $\begin{array}{l}\text { Week } \\
4\end{array}$ & $2 \mathrm{Nm}$ & 2.5 & 3.0 & $2 \mathrm{Nm}$ & 2.5 & 3.0 & And so on till week 12 \\
\hline
\end{tabular}


determine insulin sensitivity. Plasma glucose will be measured by the Autoanalyzer glucose oxidase method and plasma insulin concentrations will be determined by commercial radioimmunoassay. The $\mathrm{S}_{\mathrm{I}}$ (glucose disposal rate per unit of secreted insulin per unit time, i.e. insulin sensitivity) and $\mathrm{S}_{\mathrm{G}}$ (glucose mediated glucose disposal rate) will be calculated from a least-squares fitting of the temporal pattern of glucose and insulin throughout the IVGTT using the MINMOD program [38, 39].

\section{Oxygen uptake and energy expenditure during FES-LEC}

One week before intervention (week 1), postinterventions 1 (week 14) and 2 (week 27), peak oxygen uptake $\left(\mathrm{VO}_{2}\right)$ will be measured using a COSMED K4b2 (COSMED USA, Chicago, IL, USA) portable metabolic unit [19]. After calibration, individuals will be asked to place the mask on their face to monitor oxygen $\left(\mathrm{VO}_{2}\right)$ and carbon dioxide $\left(\mathrm{VCO}_{2}\right)$ production. A 3-min resting phase allows the participant to get used to breathing with the mask on while they are attached to the RT-300 bike. After the resting phase, $\mathrm{VO}_{2}$ will be measured during the 3-min warm-up phase, the resistance of the bike will be gradually increased by $2 \mathrm{Nm}$ every 2 min until fatigue. During testing, the servo-motor will be tuned off and the cool-down phase will then be followed by the recovery phase [19].

$\mathrm{VO}_{2}$ and $\mathrm{VCO}_{2}$ will be monitored throughout exercise to determine total energy expenditure using the Weir equation. Five minutes of recovery will be recorded to determine the efficacy of each intervention on energy expenditure and substrate utilization. Heart rate (via polar HR monitor) will be recorded every $30 \mathrm{~s}$ and blood pressure (COSMED 740) will be recorded before, every $2 \mathrm{~min}$ during cycling, and for another $5 \mathrm{~min}$ after cycling to ensure full recovery to baseline.

\section{Body composition $B M I$ and anthropometrics}

Each participant will be asked to empty their bladder and then will propel onto a wheelchair weighing scale to evaluate weight in kilograms. The wheelchair will be measured separately and the difference will be taken for the final weight. The height of each participant will be determined with the individual on his/her right side in the supine position. Two smooth wooden boards will be placed at the participant's head and heels and the distance between them corresponds to the height in nearest centimeter. The BMI $\left(\mathrm{kg} / \mathrm{m}^{2}\right)$ will be calculated as weight $(\mathrm{kg}) /$ height $\left(\mathrm{m}^{2}\right)$. Anthropometrics will be determined in duplicate by identifying the narrowest region of the trunk from sitting and lying positions. After normal expiration, a tape measure will be used around the participant's trunk to measure waist circumference (WC) $[33,40,41]$.

\section{Dual energy X-ray absorptiometry (DXA)}

DXA will be used to measure body composition in SCI individuals, specifically regional and total fat mass (FM) and fat-free mass (FFM). Total body and regional (lumbar spine, proximal femur, and forearm) DXA scans will be performed using a GE Lunar iDXA (Lunar Inc., Madison, WI, USA) bone densitometer at the Hunter Holmes VAMC hospital. All scans will be performed and analyzed using Lunar software version 10.5. After scanning, total and regional \% FM and FFM will be determined using DXA software. The longitudinal precision of total and regional body composition using DXA was recently determined in persons with SCI [42].

\section{Magnetic resonance imaging (MRI)}

Skeletal muscle CSAs will be determined before (baseline) and twice after 12-week interventions (post-interventions 1 and 2) using a 1.5-Tesla GE magnet. Transaxial images, $0.8 \mathrm{~cm}$ thick and $1.6 \mathrm{~cm}$ apart, will be taken from the hip joint to the knee joint (thigh) and from knee to the ankle (leg) using the whole-body coil $[19,20,43-46]$. T1-weighted imaging will be performed using a fast spin-echo sequence to capture visceral fat images. To measure visceral adipose tissue (VAT) and subcutaneous adipose tissue (SAT), transverse slices $(0.8$ $\mathrm{cm}$ thickness) are acquired every $0.4-\mathrm{cm}$ gap from the xyphoid process to the femoral heads. Images will be acquired in a series of two stacks with L4-L5 used as a separating point. Participants will be asked to take a deep breath in and hold their breath for $10-15 \mathrm{~s}$ to reduce the respiratory-motion artifact associated with MRI for the abdominal region [19, 29, 47].

\section{Skeletal muscle torque and fatigue}

Skeletal muscle torque and fatigue of the knee extensor muscle groups (left and right) will be evaluated at baseline, after 12 weeks at P1 and then 12 weeks after FESLEC for both groups at P2 using a Biodex isokinetic dynamometer (Biodex Medical Systems, Shirley, NY, USA). Participants will be in a seated posture with the trunk-thigh angle and the knee flexed at $90^{\circ}$ (where 0 corresponds to full knee extension). Isometric torque will be measured after adjusting the amplitude of the current to 50 and $100 \mathrm{~mA}$ (frequency $30 \mathrm{~Hz}$ and pulse duration $450 \mu \mathrm{s}$ ). Fatigue will be assessed by measuring the torque elicited at 10, 20, 30, 40, 50 60, 80, and 100 $\mathrm{Hz}$ before and immediately after intervention. Isokinetic torque will be measured at 60, 90, and 180 degrees/s using the same electrical stimulation protocol [19].

\section{Skeletal muscle biopsy}

Three biopsy samples of the vastus lateralis muscle (100 mg wet wt.) will be obtained by a 14-gauge Tru-Cut needle to compare the effects of evoked NMES + FES 
versus control on protein levels of IRS-1, GLUT-4, IGF1 and PGC-1 $\alpha$, AMPK, Akt and mTOR as well as the phosphorylation forms of AMPK, AKT, and mTOR. We will also test whether NMES + FES enhanced mitochondrial enzymatic activities and ETC compared to control. Skeletal muscle biopsies of the right vastus lateralis muscle will be obtained before training and after 12 and 24 weeks of interventions [48, 49].

Western blot analysis will be performed to determine the protein concentrations as previously described [50]. Briefly, proteins will be resolved by SDS-PAGE then transferred to two supported nitrocellulose membranes by wet electromembrane transfer at $110 \mathrm{~V}$ for $2 \mathrm{~h}$ and then blocked in 6\% bovine serum albumin (BSA)/ Tween-Tris-buffered saline (TTBS) for $1 \mathrm{~h}$. Membranes will be incubated separately with the appropriate primary antibody overnight. The membranes will be washed separately (three times for $20 \mathrm{~min}$ ) in 6\% BSA/ TTBS and incubated with appropriate secondary antibody in $4 \mathrm{~mL} 3 \%$ BSA/TTBS at $4{ }^{\circ} \mathrm{C}$ for $1 \mathrm{~h}$. The membranes will be washed (four times for $45 \mathrm{~min}$ ) in 6\% BSA/TTBS. Proteins will be visualized using an enhanced chemiluminescence detection system (GE Lifesciences) according to the manufacturer's instructions. Western blots will be quantified by scanning with A GS800 densitometer. Optical densities of the Western blots will be measured using image-analysis software (Molecular Analyst; Bio-Rad).

\section{Mitochondrial electron transport chain activities}

Samples of skeletal muscle are studied for assessment of ETC activity. Measurement of maximal enzyme activity is performed in freshly isolated detergent solubilized mitochondria using cholate as detergent. Analysis of freshly isolated samples are initially performed to assure that maximal activity of electron transport complex I is obtained. Skeletal muscle is isolated, homogenized, and a potion subjected to detergent solubilization in cholate. The enzyme activity of ETC complexes is obtained by using specific substrates and inhibitors to isolate segments of the ETC. Assays are performed in $0.1 \mathrm{M}$ phosphate buffer using spectrophotometric endpoints. Complex I activity (NADH coenzyme Q reductase) is measured following the oxidation of substrate NADH to decylubiquinol, a synthetic coenzyme $\mathrm{Q}$, as electron acceptor. Activity is measured in the presence and absence of the specific complex I inhibitor rotenone. In a similar manner, the activity of other complexes is measured using specific substrates, acceptors, and inhibitors. Complex II is measured using succinate as substrate and the reduction of 2,6 dichlorophenolindophenol as the electron acceptor followed as spectrophotometric indicator, with and without thenoyltrifluoroacetone as the inhibitor of complex II. Complex III activity is measured using the reduced synthetic coenzyme Q molecule decylubiquinol as substrate, oxidized cytochrome c as acceptor, and antimycin-A as the complex III specific inhibitor. The reduction of cytochrome $\mathrm{c}$ as acceptor is followed as the spectrophotometric endpoint. Complex IV is measured by following the first-order oxidation of added exogenous reduced cytochrome $\mathrm{c}$ using azide as the specific inhibitor [51]. Citrate synthase, a tricarboxylic acid cycle component enzyme, is measured as an indicator of mitochondrial mass [51-55].

\section{Statistical analyses}

T-tests and Pearson chi-square tests will be used to compare characteristics that may act as confounding variables, including age, level of injury, time since injury, $\% \mathrm{FM}$, as well as the three outcome variables $(\mathrm{Si}, \mathrm{Sg}$, $\mathrm{VO}_{2}$ ) to ensure that each group is not different with respect to each variable at baseline. A repeated-measures ANOVA will be performed with glucose effectiveness as the primary study outcome and effects for treatment group (NMES + FES versus control), time (baseline and post-interventions 1 and 2), and the interaction between the two factors included in the model. Similar repeated measured ANOVA models will be fit with each of the body composition, metabolic profile, protein expression, and ETC measures (Aim 3). All statistical analysis will be performed at the 0.05 level with SAS V9.4 (Cary, NC, USA).

\section{Sample size}

We have acquired pilot data for all outcomes of this project. Glucose effectiveness possesses the smallest effect size from baseline to follow-up with NMES-RT showing a mean baseline effectiveness of 0.01716 and posttreatment mean of 0.02258 . Cohen's $f$ was found to be 0.271 using a sample variance of 0.0001 [25]. Assuming the correlation between the pre- and post-treatment measurements is 0.3735 and three total measurements are acquired, 38 individuals will need to complete the study at $90 \%$ power using a Type- 1 error rate of 0.05 . At least 48 participants will need to be recruited, adjusting for a $20 \%$ dropout rate. All sample sizes were calculated using the software G*Power (V3.1.9.2). A sample size of 24 was calculated using insulin sensitivity data without regard to dropout rate.

Other factors, such as insulin sensitivity and $\mathrm{VO}_{2}$, are considered; each representing larger effect sizes than glucose effectiveness $(f=0.313$ and $f=0.432$, respectively). Our study would result in a power of $97.51 \%$ and $99.82 \%$ for observing the baseline to follow-up difference between the NMES + FES and Control + FES groups, provided the correlation between baseline and follow-up measurements are 0.4 for the outcomes. 


\section{Discussion}

In the last 10 years, there have been significant advances in our understanding of the body composition changes and metabolic profile after SCI. Skeletal muscle atrophy is accompanied with infiltration of ectopic adipose tissue both in the paralyzed muscle and in trunk region that facilitates the development of central adiposity. In persons with chronic SCI, VAT and SAT are $58 \%$ and $48 \%$ greater than healthy ablebodied controls, respectively [56-58]. Ectopic adiposity is simply defined as storage of fat in non-adipose tissue sites and characterized by increasing the release of inflammatory cytokines. These changes in body fat distribution occur in conjunction with excessive production of hepatic glucose in the absence of autonomic nervous system control after SCI in those with injuries above the fourth thoracic segment [59]. The increase in VAT is negatively related to high density lipoprotein cholesterol (HDL-C) and insulin resistance, with men being 1.8-2.6 times more susceptible to accumulation of VAT than women after SCI [60]. Several anthropometric and imaging measurements have been proposed to accurately quantify changes in muscle size and visceral adiposity [61, 62]. Sumrell et al. have recommended SCI cutoffs for central adiposity that can simply be used to identify cardiometabolic risks using seated/supine circumferences in men with chronic SCI [62].

Today, exercise is still considered a feasible, accessible, and non-pharmacological approach that can overcome several of the cardio-metabolic risk factors after SCI. Upper extremity cycling exercise and/or circuit resistance training are limited to small muscle mass above the level of lesion and do not exercise large muscle groups in the lower extremities. Moreover, persons with tetraplegia ( $\geq$ C6 SCI) are less likely to benefit from upper extremity training at intensities that can improve cardiometabolic risk parameters [63]. This renders exercise limited to use of the upper extremities as an ineffective method to attenuate the deterioration in metabolic profile and body composition after SCI. Another form of exercise is FES-LEC, which effectively restores muscle size and improve of cardio-metabolic risk factors after SCI $[64,65]$. However, FES-LES is limited by low exercise intensity, oxygen uptake, and rapid muscle fatigue. To offset for these limitations, the use of hybrid exercise by combining both upper extremities and FES cycling has been shown to improve cardiovascular outcomes more than FES-LEC [66]. Arm cranking exercise (ACE) in combination with FES-LEC displayed increasing muscle oxygenation $\left(\mathrm{StO}_{2}\right)$ at $40 \%, 60 \%$, and $80 \%$ of individuals' peak $\mathrm{VO}_{2}$ compared to ACE only that showed decreases in $\mathrm{StO}_{2}$ and FES-LEC only that had steady increases in just $60 \%$ and $80 \%$ peak $\mathrm{VO}_{2}$. The combination of ACE +
FES-LEC demonstrates better oxygenation than either ACE or FES-LEC alone [66]. These forms of hybrid-FES training are more suited for high-intensity, high-volume exercise training than FES-cycling only and require intact upper extremity function.

There are currently no guidelines on how to maximize the benefits of FES-LEC to improve the cardio-metabolic health variables after SCI. Several strategies have been recommended to maximize the training outcomes of FES-LEC. Raising the stimulation amplitude to $300 \mathrm{~mA}$ has been proposed to increase the neuromuscular response and increase energy expenditure; however, this option is not FDA-approved for most of the available FES bikes [67, 68]. The maximum current on most of the commercially available FES bikes is $140 \mathrm{~mA}$. Moreover, this high level of stimulation amplitude may increase the risk of developing autonomic dysreflexia. Another alternative approach is to increase the frequency of FES-LEC training to 3-7 days/week [17]. This approach is limited by poor compliance in longitudinal trials. We have studied the exercise adherence to homebased FES-LEC in 17 individuals with SCI. We have found that just maintaining a frequency of three times rather than two times/week decreased adherence from $72 \%$ in the first eight weeks to $63 \%$ in the second eight weeks [65]. A case report has shown showed that a frequency of 2-3 times per week is likely to increase adherence up to 54 months of training [69]. This is accompanied with reasonable gain in lean mass, on an average of $0.8-1.6 \mathrm{~kg}$, in persons with SCI [23, 70]. Another consideration is the frequency of training and the time allowed for recovery between sessions. Our cross-sectional data showed that force remained reduced by $>20 \%$ for $48-72 \mathrm{~h}$ after an acute bout of FES-LEC in men with SCI [68]. This is likely caused by to exercise induced muscle damage that typically occurs as result of chronic disuse of the paralyzed muscles. It is vital to initiate appropriate mechano-stressor stimuli to optimize skeletal muscle adaptations as a large paracrine gland $[71,72]$. Moreover, FES-LEC is considered an appropriate aerobic training paradigm that may stimulate an increase in mitochondrial capacity and help partitioning of substrate utilization of IMF as primary source of energy during exercise and further improved insulin sensitivity [73].

Surface NMES-RT has been shown to increase muscle hypertrophy, increase fatigue resistance, and improve oxygen reuptake in the muscles [20-25]. In a randomized clinical trial, Gorgey et al. used TRT in combination with NMES-RT to determine the impact on body composition and metabolic variables in men after SCI compared to a TRT-only control [25]. The study reports an almost $20 \mathrm{~cm}^{2}$ increase for whole thigh and absolute muscle CSA, in addition to an $8-12 \%$ decrease in VAT 
and marginal $15 \%$ increases in BMR for the TRT + RT group, with no changes in the TRT only group in thigh muscle CSA or BMR. The increases in lean mass and BMR combined with the decreases in VAT content after TRT + RT may improve cardiometabolic health, insulin sensitivity, and prevent obesity [25]. Moreover, we and others have shown that NMES-RT is accompanied with decrease infiltration of IMF, reduce peripheral muscle fatigue by $30 \%$, increase muscle quality and slowness of rise time, and increase mitochondrial activity after SCI $[74,75]$.

\section{Limitations}

Dietary intake may confound effects of the training and increased muscle mass. However, a recent trial showed that protein intake over an eight-week period would not trigger increase in muscle size in persons with SCI [76]. The dietary records are evaluated on a weekly basis to monitor caloric intake. Any intake that exceeds 300$500 \mathrm{kcal} /$ week above their baseline BMR will be flagged. Another limitation is that close to $20 \%$ of the population may not benefit from NMES/FES applications, particularly those with lower motor neuron injury and denervation of skeletal muscles, thus limiting eligibility for enrollment and reducing the pool of patients who may benefit from NMES/FES as a therapy. Another limitation is those who do not respond to NMES due to lower motor neuron denervation (LMN) or intolerance to electrical stimulation [77]. Currently, a clinical trial is underway to test the efficacy of using long pulse width stimulation to restore muscle size in those with LMN after SCI [77].

We proposed a two-center study to facilitate recruitment of 48 participants. We have included an age range of 18-65 years, women, and those with AIS C, provided a wheelchair is their primary method of mobility, who possess no functional movement sublesionally and use non-weight bearing activities only. The feasibility of this approach may be called into question because any benefits may be lost with the cessation of training. Our protocol emphasizes long-term compliance and adherence to maximize benefits. We have tested the feasibility of home-based NMES-RT over an eight-week period utilizing video-telecommunication service. The result showed that the trained knee extensor muscle CSA increased by $18 \%$ compared to the controlled limb [78]. This may serve as a continuation of the current trial and bases for establishing future home-based clinical trials to maximize recruitment and reduce the cost associated with travel time.

Previously, the barriers of commitment to long-term intervention have been highlighted [79]. One of these barriers is transportation, which remains of a great concern regarding retention in the study. To further alleviate transportation burdens, a research technician has been budgeted to escort participants in a VA van to certain locations for study measurements.

In conclusion, the current clinical trial endeavors to increase the cardio-metabolic benefits of FES-LEC through the addition of NMES-RT. This may result in improvement of aerobic fitness and metabolic health and reduce the severity of chronic secondary healthrelated consequences. The study will provide mechanistic insights regarding molecular underpinnings of the benefits of the two different paradigms of electrical stimulation to chronically paralyzed muscles. One paradigm is mimicking RT using a weight-lifting approach and the other generates low tension stimulation mimicking aerobic-type training. It will be of interest to our population to understand the additive effects of both approaches on the cardio-metabolic outcome variables in persons with SCI. This could be simply integrated as an effective rehabilitation intervention in the clinical setting shortly after completion of the study.

\section{Trial status}

The trial has been active and open for enrollment since August 2015 with anticipated completion date of September 2020. The study was approved by the local ethics committee at McGuire VA Medical Center and Virginia Commonwealth University. The trial is registered in clinicaltrials.gov, no. NCT02660073. Protocol version-3 dated 25 November 2015. Recruitment started August 2015 and will end March 2020.

\section{Acknowledgements}

We would like to thank the participants who gave their time and energy to our study. We would like to thank Chen Qun for his technical expertise in Mitochondria analysis. We would also like also to thank the MRI technicians in the Radiology department for their work in obtaining the images as well as the nurses in the Clinical Research Center of MCV hospital for their valuable time and effort. We also thank Hunter Holmes McGuire Research Institute and Spinal Cord Injury Services and Disorders for the use of their facilities in our human research trials.

\section{Authors' contributions}

ASG: designed the study, supervised all aspects of the protocol; wrote the manuscript, drafting and edit the submission, will help in future interpretation of the data; REK and JCD: recruited and trained patients, data collection and analysis, wrote the manuscript; JR: performed all muscle biopsy samples; WC, RG, RK, LG, TC, TL, EL, RA: medical monitoring of the study, screening for patients, MRI accessibility; administering IVGTT; mitochondrial, analyses. All authors approved the final version of the manuscript. AS: statistical consultant, provided power analysis and randomization of the study; CC: helped designing the study, drafting and editing the submission, will help in protein and RNA analyses and future interpretation of the data.

\section{Funding}

This study was supported by the DoD-CDRMP (W81XWH-14-SCIRP-CTA) as well as Dr. Bauman's Center Grant B2020-C. The funding agents have nothing to do with the design of the study and data collection, analysis, and interpretation of data and in writing the manuscript should be declared. 


\section{Availability of data and materials}

The data will not be publicly available and only data will be available upon written request to the PI.

\section{Pe, and Sharing of Data}

Participants will be assigned a unique study number upon entrance into the study. All forms will be coded with this number rather than the patient's name, social security number, or other identifying information. Participant identifiers will be available to the $\mathrm{Pl}$ and authorized research coordinator via a password protected database and/or coding sheets kept in locked areas of the research personnel offices. The principal investigator and study personnel will keep a master.

The Pl, or designee, may share data collected through study screening and/ or participation with the participant or their primary care provider if there is a likelihood that the participant could benefit medically or otherwise from having the information and subjects will be notified of this through the informed consent process and in the written consent document.

\section{C1. Data Manage}

The data manager's duties will include continuous data coordination, management, and monitoring for the project. The data manager is responsible for the development and maintenance of a comprehensive database and in the preparation of data for statistical analysis for the study. Also, the data manager will be responsible for supervising and facilitating electronic (and possibly manual) data entry and data collection tools, including the physical handling of paper data forms and any other collection devices. Also, the data manager will assist the biostatistician in testing data forms and transferring data out of the database for preparation and analysis.

\section{C2. Database Management, Data Monitoring, and Quality Control}

Subject list that links the subject ID number with personal identifiers. This master list and the study documents and research records will be maintained in separate locked cabinets in a locked research office. All study records will be maintained indefinitely. Individuals from the local institutional review board (IRB) may look at these records as part of their duties. Confidentiality of these records will be protected to the extent possible under existing regulations and laws. Participant's name and other protected health information will not appear in any published paper or presentation related to this study. It should be noted that representatives of the McGuire Research Institute (MRI) local IRB are eligible to review research records as part of their responsibility to protect human subjects in research. Additionally, research records may be reviewed by appropriate federal agencies, such as the Food and Drug Administration (FDA), as required by law.

Data entry will be facilitated by the development of an MS Excel data entry sheets. The MS Excel front end has built-in first-level automatic checks to ensure data integrity and validity regarding data type and range, as well as data completeness. Summary and raw data reports will be integral parts of the database design to help the investigators routinely inspect entered data. Each participant will have a summary excel sheet coded by his/her assigned study ID code. The excel sheet will be composed of three tabs (baseline, post-intervention 1 and post-intervention 1). After subject's data has been entered into the database, a 100\% data audit is performed to assure accuracy of the entered and constructed data. Any systematic problems should be detected than $1 \%$ error rate. If, however, the error rate is larger than $1 \%$, the effected subset will be audited on a more frequent basis until the problem is resolved. Finally, the original databases will be housed on the VA passwordsecured drive that only the PI and his research coordinator will have access to it. The data manager is tasked to export data from the back-end and store data in an "analysis ready" format for subsequent data analysis using SPSS 24 statistical analysis packages. Technical support of the database applications will be provided on an ongoing basis throughout the study through the manuscript preparation phase.

\section{C4. Data Flow}

Data will be obtained using traditional data collection forms and exported electronic Excel sheet files format that automatically generated during for energy expenditure, body composition assessment using DXA and MRI as well as secured templates for IVGTT. Duplicates of the traditional data collection forms will be securely sent to the Data Management Center and the originals will be securely stored at McGuire VA Hospital. Data collected through traditional data collection forms will be entered by hand into MS Excel sheet by the research study coordinator. Finally, data will be copied onto a CD with no personal identifiers or a secure USB drive and securely sent to the Data Management center where they will be uploaded and imported into Microsoft Excel (original files will remain at McGuire). The data will be stored on a secure VA flash drive with incremental backups. C5. Data Center Confidentiality and Security All database applications will be password-protected to ensure security of entered data and housed in the McGuire VA Medical Center servers located behind the firewall. Only the PI and other approved personnel will have access to the data. There will be several levels of security and access will depend upon the personnel's need. Exported data will not contain any information regarding patient identity (i.e. name, social security number, address, birthday, medical record number, and any other identifying information). Subject ID or similar naming convention will identify each participant, thus ensuring strict confidentiality of all study data. The server that the database is maintained on will also have its own level of security with access to the data only by password, thus ensuring two levels of security. The data manager will be responsible for keeping a (local) redundant back-up of all active databases. All study data will be backed-up on a weekly basis onto CD-ROM or external hard drive. The copies will be kept in a fireproof safe in the data manager's office.

\section{Ethics approval and consent to participate}

The study is approved by McGuire Research Inst. and Virginia Commonwealth University IRBs. All participants will approve and sign a written informed consent.

\section{Consent for publication}

Not applicable.

\section{Competing interests}

The authors declare that they have no competing interests.

\section{Author details}

${ }^{1}$ Spinal Cord Injury \& Disorders Service, Hunter Holmes McGuire VA Medical Center, Richmond, VA, USA. ${ }^{2}$ Department of Physical Medicine \& Rehabilitation, Virginia Commonwealth University, Richmond, VA, USA. ${ }^{3}$ Endocrinology Service, Hunter Holmes McGuire VA Medical Center, Richmond, VA, USA. ${ }^{4}$ Endocrine Division, School of Medicine Virginia Commonwealth University, Richmond, VA, USA. ${ }^{5}$ Radiology Service, Hunter Holmes McGuire VA Medical Center, Richmond, VA, USA. ${ }^{6}$ Department of Biostatistics, School of Medicine Virginia Commonwealth University, Richmond, VA, USA. ${ }^{7}$ Cardiology Service, Hunter Holmes McGuire VA Medical Center, Richmond, VA, USA. ${ }^{8}$ Division of Cardiology, Department of Internal Medicine, Pauley Heart Center Virginia Commonwealth University, Richmond, VA, USA. ${ }^{9}$ Center for the Medical Consequences of Spinal Cord Injury, James J Peters VA Medical Center, Bronx, NY, USA. ${ }^{10}$ Departments of Medicine and Rehabilitation Medicine, Icahn School of Medicine, New York, NY, USA.

Received: 31 March 2019 Accepted: 6 July 2019

Published online: 23 August 2019

\section{References}

1. Gorgey AS, Dolbow DR, Dolbow JD, Khalil RK, Castillo C, Gater DR. Effects of spinal cord injury on body composition and metabolic profile - part I. J Spinal Cord Med. 2014;37:693-702.

2. Gorgey AS, Mather KJ, Poarch H, Gater DR. Influence of motor complete spinal cord injury on visceral and subcutaneous adipose tissue measured by multiaxial magnetic resonance imaging. I Spinal Cord Med. 2011;34(1):99-109.

3. Gorgey AS, Gater DR. Regional and relative adiposity patterns in relation to carbohydrate and lipid metabolism in men with spinal cord injury. Appl Physiol Nutr Metab. 2011;36(1):107-14.

4. National Spinal Cord Injury Statistical Center. https:/www.nscisc.uab.edu/. Accessed 27 Mar 2019.

5. DeVivo MJ, Go BK, Jackson AB. Overview of the national spinal cord injury statistical center database. J Spinal Cord Med. 2002;25(4):335-8.

6. Strauss DJ, Devivo MJ, Paculdo DR, Shavelle RM. Trends in life expectancy after spinal cord injury. Arch Phys Med Rehabil. 2006;87(8):1079-85.

7. DeVivo MJ. Causes and costs of spinal cord injury in the United States. Spinal Cord. 1997;35(12):809-13.

8. Haskell WL, Lee IM, Pate RR, Powell KE, Blair SN, Franklin BA, et al. Physical activity and public health: updated recommendation for adults from the 
American College of Sports Medicine and the American Heart Association. Med Sci Sports Exerc. 2007;39(8):1423-34

9. Martin Ginis KA, van der Scheer JW, Latimer-Cheung AE, Barrow A, Bourne C, Carruthers $\mathrm{P}$, et al. Evidence-based scientific exercise guidelines for adults with spinal cord injury: an update and a new guideline. Spinal Cord. 2018:56:308-21.

10. Ginis KA, Hicks AL, Latimer AE, Warburton DE, Bourne C, Ditor DS, et al. The development of evidence-informed physical activity guidelines for adults with spinal cord injury. Spinal Cord. 2011;49:1088-96.

11. Kanzleiter T, Rath M, Görgens SW, Jensen J, Tangen DS, Kolnes AJ, et al. The myokine decorin is regulated by contraction and involved in muscle hypertrophy. Biochem Biophys Res Commun. 2014;450(2):1089-94.

12. Pedersen BK, Febbraio MA. Muscles, exercise and obesity: skeletal muscle as a secretory organ. Nat Rev Endocrinol. 2012;8:457-65.

13. Pedersen BK, Febbraio MA. Muscle as an endocrine organ: focus on musclederived interleukin-6. Physiol Rev. 2008;88:1379-406.

14. Aksnes AK, Hjeltnes N, Wahlström EO, Katz A, Zierath JR, WallbergHenriksson $\mathrm{H}$. Intact glucose transport in morphologically altered denervated skeletal muscle from quadriplegic patients. Am J Phys. 1996;271:E593-600

15. Arany Z. PGC-1 coactivators and skeletal muscle adaptations in health and disease. Curr Opin Genet Dev. 2008;18(5):426-34.

16. Sacheck JM, Hyatt JP, Raffaello A, Jagoe RT, Roy RR, Edgerton VR, et al. Rapid disuse and denervation atrophy involve transcriptional changes similar to those of muscle wasting during systemic diseases. FASEB J. 2007;21(1):140-55.

17. Gorgey AS, Dolbow DR, Dolbow JD, Khalil RK, Gater DR. The effects of electrical stimulation on body composition and metabolic profile after spinal cord injury - Part II. J Spinal Cord Med. 2015;38(1):23-37.

18. Hettinga DM, Andrews BJ. Oxygen consumption during functional electrical stimulation assisted exercise in persons with spinal cord injury: implications for fitness and health. Sports Med. 2008:38:825-38.

19. Gorgey AS, Poarch HJ, Dolbow DD, Castillo T, Gater DR. Effect of adjusting pulse durations of functional electrical stimulation cycling on energy expenditure and fatigue after spinal cord injury. J Rehabil Res Dev. 2014; 51(9):1455-68

20. Mahoney ET, Bickel CS, Elder C, Black C, Slade JM, Apple D Jr, et al. Changes in skeletal muscle size and glucose tolerance with electrically stimulated resistance training in subjects with chronic spinal cord injury. Arch Phys Med Rehabil. 2005;86(7):1502-4.

21. Dudley GA, Castro MJ, Rogers S, Apple DF Jr. A simple means of increasing muscle size after spinal cord injury: a pilot study. Eur J Appl Physiol Occup Physiol. 1999;80(4):394-6.

22. Sabatier MJ, Stoner L, Mahoney ET, Black C, Elder C, Dudley GA, et al. Electrically stimulated resistance training in SCl individuals increases muscle fatigue resistance but not femoral artery size or blood flow. Spinal Cord. 2006:44(4):227-33.

23. Gorgey AS, Mather KJ, Cupp H, Gater DR. Effects of Resistance Training on adiposity and metabolism after Spinal Cord Injury. Med Sci Sports Exerc. 2012;44(1):165-74.

24. Ryan TE, Brizendine JT, Backus D, McCully KK. Electrically induced resistance training in individuals with motor complete spinal cord injury. Arch Phys Med Rehabil. 2013;94:2166-73.

25. Gorgey AS, Khalil RE, Gill R, Gater DR, Lavis TD, Christopher PC, et al. Lowdose testosterone and evoked resistance exercise after spinal cord injury on cardio-metabolic risk factors: an open-label randomized clinical trial. J Neurotrauma. 2019. https://doi.org/10.1089/neu.2018.6136.

26. Reginster JY, Burlet N. Osteoporosis: A Still Increasing Prevalence. Bone. 2006;38(2):4-9.

27. Gorgey AS, Khalil RE, Lester RM, Dudley GA, Gater DR. Paradigms of lower extremity electrical stimulation training after spinal cord injury. J Vis Exp. 2018;(132). doi: https://doi.org/10.3791/57000.

28. Gorgey AS, Shepherd C. Skeletal muscle hypertrophy and decreased intramuscular fat after unilateral resistance training in spinal cord injury: case report. J Spinal Cord Med. 2010;33(1):90-5.

29. Gorgey AS, Mahoney E, Kendall T, Dudley GA. Effects of neuromuscular electrical stimulation parameters on specific tension. Eur J Appl Physiol. 2006;97(6):737-44.

30. Gorgey AS, Black CD, Elder CP, Dudley GA. Effects of electrical stimulation parameters on fatique in skeletal muscle. J Orthop Sports Phys Ther. 2009; 39(9):684-92.
31. Ryan TE, Erickson ML, Young HJ, McCully KK. Case report: endurance electrical stimulation training improves skeletal muscle oxidative capacity in chronic spinal cord injury. Arch Phys Med Rehabil. 2013; 94(12):2559-61.

32. Dolbow DR, Gorgey AS, Ketchum JM, Gater DR. Home-based functional electrical stimulation cycling enhances quality of life in individuals with spinal cord injury. Top Spinal Cord Inj Rehabil. 2013;19(4):324-9.

33. Gorgey AS, Chiodo AE, Zemper ED, Hornyak JE, Rodriguez GM, Gater DR. Relationship of spasticity to soft tissue body composition and the metabolic profile in persons with chronic motor complete spinal cord injury. J Spinal Cord Med. 2010;33(1):6-15.

34. Collins EG, Gater D, Kiratli J, Butler J, Hanson K, Langbein WE. Energy cost of physical activities in persons with spinal cord injury. Med Sci Sports Exerc. 2010;42(4):691-700.

35. Vermeulen A, Verdonck L, Kaufman JMA. Critical evaluation of simple methods for the estimation of free testosterone in serum. J Clin Endocrinol Metab. 1999;84(10):3666-72.

36. Manns PJ, McCubbin JA, Williams DP. Fitness, inflammation, and the metabolic syndrome in men with paraplegia. Arch Phys Med Rehabil. 2005; 86(6):1176-81

37. Johnston TE, Modlesky CM, Betz RR, Lauer RT. Muscle changes following cycling and/or electrical stimulation in pediatric spinal cord injury. Arch Phys Med Rehabil. 2011;92(12):1937-43.

38. Matthews DR, Hosker JP, Rudenski AS, Naylor BA, Treacher DF, Turner RC. Homeostasis model assessment: insulin resistance and beta-cell function from fasting plasma glucose and insulin concentrations in man. Diabetologia. 1985;28:412-9.

39. Gorgey AS, Harnish CR, Daniels JA, Dolbow DR, Keeley A, Moore J, et al. A report of anticipated benefits of functional electrical stimulation after spinal cord injury. J Spinal Cord Med. 2012;35(2):107-12.

40. Clasey JL, Gater DR Jr. A comparison of hydrostatic weighing and air displacement plethysmography in adults with spinal cord injury. Arch Phys Med Rehabil. 2005;86:2106-13.

41. Buchholz AC, Bugaresti JM. A review of body mass index and waist circumference as markers of obesity and coronary heart disease risk in persons with chronic spinal cord injury. Spinal Cord. 2005:43(9):513-8.

42. Lester RM, Ghatas MP, Khan RM, Gorgey AS. Prediction of thigh skeletal muscle mass using dual energy $\mathrm{x}$-ray absorptiometry compared to magnetic resonance imaging after spinal cord injury. J Spinal Cord Med. 2019. https://doi.org/10.1080/10790268.2019.1570438.

43. Castro MJ, Apple DF Jr, Hillegass EA, Dudley GA. Influence of complete spinal cord injury on skeletal muscle cross-sectional area within the first 6 months of injury. Eur J Appl Physiol Occup Physiol. 1999:80(4):373-8.

44. Gorgey AS, Dudley GA. Skeletal muscle atrophy and increased intramuscular fat after incomplete spinal cord injury. Spinal Cord. 2007;45(4):304-9.

45. Elder CP, Apple DF, Bickel CS, Meyer RA, Dudley GA. Intramuscular fat and glucose tolerance after spinal cord injury--a cross-sectional study. Spinal Cord. 2004;42(12):711-6.

46. Gorgey AS, Cho GM, Dolbow DR, Gater DR. Differences in current amplitude evoking leg extension in individuals with spinal cord injury. NeuroRehabilitation. 2013;33(1):161-70.

47. Gorgey AS, Mather KJ, Gater DR. Central adiposity associations to carbohydrate and lipid metabolism in individuals with complete motor spinal cord injury. Metabolism. 2011;60(6):843-51.

48. Bickel CS, Cross JM, Bamman MM. Exercise dosing to retain resistance training adaptations in young and older adults. Med Sci Sports Exerc. 2011; 43(7):1177-87.

49. Blake GJ, Ridker PM. Novel clinical markers of vascular wall inflammation. Circ Res. 2001;89(9):763-71.

50. Gorgey AS, Graham ZA, Bauman WA, Cardozo C, Gater DR. Abundance in proteins expressed after functional electrical stimulation cycling or arm cycling ergometry training in persons with chronic spinal cord injury. J Spinal Cord Med. 2017;40(4):439-48.

51. Ritov VB, Menshikova EV, Azuma K, Wood R, Toledo FG, Goodpaster BH, et al. Deficiency of electron transport chain in human skeletal muscle mitochondria in type 2 diabetes mellitus and obesity. Am J Physiol Endocrinol Metab. 2010;298(1):E49-E58.

52. Brass EP, Hiatt WR, Gardner AW, Hoppel CL. Decreased NADH dehydrogenase and ubiquinol-cytochrome c oxidoreductase in peripheral arterial disease. Am J Physiol Heart Circ Physiol. 2001;280(2):H603-9. 
53. Talmadge RJ, Castro MJ, Apple DF Jr, Dudley GA. Phenotypic adaptations in human muscle fibers 6 and 24 wk after spinal cord injury. J Appl Physiol. 2002;92(1):147-54.

54. Castro MJ, Apple DF Jr, Staron RS, Campos GE, Dudley GA. Influence of complete spinal cord injury on skeletal muscle within 6 mo of injury. J Appl Physiol. 1999:86(1):350-8.

55. Kjaer M, Dela F, Sørensen FB, Secher NH, Bangsbo J, Mohr T, et al. Fatty acid kinetics and carbohydrate metabolism during electrical exercise in spinal cordinjured humans. Am J Physiol Regul Integr Comp Physiol. 2001;281(5):R1492-8.

56. Mojtahedi MC, Valentine RJ, Arngrimsson SA, Wilund KR, Evans EM. The association between regional body composition and metabolic outcomes in athletes with spinal cord injury. Spinal Cord. 2008;46:192-7.

57. Edwards LA, Bugaresti JM, Buchholz AC. Visceral adipose tissue and the ratio of visceral to subcutaneous adipose tissue are greater in adults with than in those without spinal cord injury, despite matching waist circumferences. Am J Clin Nutr. 2008;87(3):600-7.

58. Maruyama Y, Mizuguchi M, Yaginuma T, Kusaka M, Yoshida H, Yokoyama K, et al. Serum leptin, abdominal obesity and the metabolic syndrome in individuals with chronic spinal cord injury. Spinal Cord. 2008;46:494-9.

59. Rankin KC, O'Brien LC, Segal L, Khan MR, Gorgey AS. Liver adiposity and metabolic profile in individuals with chronic spinal cord injury. Biomed Res Int. 2017;2017:1364818

60. Gorgey AS, Farkas GJ, Dolbow DR, Khalil RE, Gater DR. Gender dimorphism in central adiposity may explain metabolic dysfunction after spinal cord injury. PM R. 2017;10(4):338-48.

61. Wade RC, Gorgey AS. Anthropometric prediction of skeletal muscle crosssectional area in persons with spinal cord injury. J Appl Physiol. 2017;122(5): 1255-61.

62. Sumrell RM, Nightingale TE, McCauley LS, Gorgey AS. Anthropometric cutoffs and associations with visceral adiposity and metabolic biomarkers after spinal cord injury. PLoS One. 2018;13(8):e0203049.

63. Fisher JA, McNelis MA, Gorgey AS, Dolbow DR, Goetz LL. Does upper extremity training influence body composition after spinal cord injury? Aging Dis. 2015;6(4):271-81.

64. Griffin L, Decker MJ, Hwang JY, Wang B, Kitchen K, Ding Z, et al. Functional electrical stimulation cycling improves body composition, metabolic and neural factors in persons with spinal cord injury. J Electromyogr Kinesiol. 2009;19(4):614-22.

65. Dolbow DR, Gorgey AS, Ketchum JM, Moore JR, Hackett LA, Gater DR. Exercise adherence during home-based functional electrical stimulation cycling by individuals with spinal cord injury. Am J Phys Med Rehabil. 2012; 91(11):922-30.

66. Hasnan N, Ektas N, Tanhoffer Al, Tanhoffer R, Fornusek C, Middleton JW, et al. Exercise responses during functional electrical stimulation cycling in individuals with spinal cord injury. Med Sci Sports Exerc. 2013;45: $1131-8$.

67. Hunt KJ, Hosmann D, Grob M, Saengsuwan J. Metabolic efficiency of volitional and electrically stimulated cycling in able-bodied subjects. Med Eng Phys. 2013;35(7):919-25.

68. Duffell LD, de N Donaldson N, Newham DJ. Why is the metabolic efficiency of FES cycling low? IEEE Trans Neural Syst Rehabil Eng. 2009;17(3):263-9.

69. Dolbow DR, Gorgey AS, Khalil RK, Gater DR. Effects of a fifty-six-month electrical stimulation cycling program after tetraplegia: case report. J Spinal Cord Med. 2017:40(4):485-8.

70. Gorgey AS, Caudill C, Khalil RE. Effects of once weekly NMES training on knee extensors fatigue and body composition in a person with spinal cord injury. J Spinal Cord Med. 2016;39(1):99-102.

71. Bickel CS, Slade JM, Haddad F, Adams GR, Dudley GA. Acute molecular responses of skeletal muscle to resistance exercise in able-bodied and spinal cord-injured subjects. J Appl Physiol. 1985;94(6):2255-62.

72. Yarar-Fisher C, Bickel CS, Windham ST, McLain AB, Bamman MM. Skeletal muscle signaling associated with impaired glucose tolerance in spinal cordinjured men and the effects of contractile activity. J Appl Physiol (1985). 2013;115(5):756-64.

73. Kjaer M, Mohr T, Biering-Sørensen F, Bangsbo J. Muscle enzyme adaptation to training and tapering-off in spinal-cord-injured humans. Eur J Appl Physiol. 2001;84(5):482-6

74. Holman ME, Gorgey AS. Testosterone and resistance training improve muscle quality in spinal cord injury. Med Sci Sports Exerc. 2019;51:1591-8.

75. Skold C, Lonn L, Harms-Ringdahl K, Hultling C, Levi R, Nash M, et al. Effects of functional electrical stimulation training for six months on body composition and spasticity in motor complete tetraplegic spinal-injured individuals. J Rehabil Med. 2002:34:25-32.

76. Yarar-Fisher C, Polston KFL, Eraslan M, Henley KY, Kinikli Gl, Bickel CS, et al. Paralytic and nonparalytic muscle adaptations to exercise training versus high-protein diet in individuals with long-standing spinal cord injury. J Appl Physiol (1985). 2018;125(1):64-72.

77. Testosterone and Long Pulse Stimulation After SCl. (2017, Nov 17). Retrieved Mar 25, 2019, from ClinicalTrials.gov: https://clinicaltrials.gov/ct2/show/ NCT03345576? cond=long+pulse+width+stimulation\&rank=1.

78. Gorgey AS, Lester RM, Wade RC, Khalil RE, Khan RK, Anderson ML, et al. A feasibility pilot using telehealth videoconference monitoring of home-based NMES resistance training in persons with spinal cord injury. Spinal Cord Ser Cases. 2017:3:17039.

79. Gorgey AS. Exercise awareness and barriers after spinal cord injury. World J Orthop. 2014;5(3):158-62.

\section{Publisher's Note}

Springer Nature remains neutral with regard to jurisdictional claims in published maps and institutional affiliations.
Ready to submit your research? Choose BMC and benefit from:

- fast, convenient online submission

- thorough peer review by experienced researchers in your field

- rapid publication on acceptance

- support for research data, including large and complex data types

- gold Open Access which fosters wider collaboration and increased citations

- maximum visibility for your research: over $100 \mathrm{M}$ website views per year

At BMC, research is always in progress.

Learn more biomedcentral.com/submissions 